\title{
Mobile Ad-hoc Networks: A Survey on multipath routing protocols
}

Mrs.L. D. Sujithra Devi/ Assistant Professor/ Department of Information Technology/ Rathinam Technical Campus, Coimbatore.

Mrs. A. Praveena/ Assistant Professor/ Department of Artificial Intelligence \& Data Science/ Rathinam Technical Campus, Coimbatore.

Mrs. B.Reena /Assistant Professor/ Department of Computer science and Engineering/ Hindusthan College of engineering and Technology, Coimbatore.

Mrs. G.Anandhi/ Assistant Professor/ Department of Information Technology/ Dr.Mahalingam College of Engineering and Technology, Pollachi,TN.

Mrs. M.Sowmya/ Assistant Professor/ Department of CSE/ GSSS Institute of engineering and Technology for Women Mysuru, Karnataka.

\begin{abstract}
:
A Mobile Ad Hoc Network (MANETs) connects mobile nodes without any base station. These nodes in the network can change the topology dynamically and transfer the data among themselves. The nodes in the MANET are categorized based on the resource factors like memory, computation, and power levels. The dynamic change in route makes the connection of the destination node more complex. Sometimes, it results in link failure, and hence the primary route is failed, which means an alternative route is required to transmit the packets. It required multiple paths from the source node to destination node with a stable path connecting the source node. This issue makes MANET routing a crucial task. To address these problems, multipath routing in MANET is discussed in this paper. Multipath routing provides various paths for a single source node to a single destination node. It is more important to consider load balancing and fault tolerance when establishing the multipath routing mechanism. This paper describes the various type of challenges along with their respective multipath routing protocols in MANETs.
\end{abstract}

Keywords: MANET, Multipath routing, Fault tolerance, load balancing, routing protocol

\section{Introduction:}

MANETs are made up of a mobility node for sharing data dynamically without any base station. MANETs have the potential to be implemented in a wide range of circumstances. These conditions need the transmission of contest signals to insubstantial sensors that are dropped and scattered throughout the ground to detect dangerous substances from high altitudes. Basic scenarios like meeting on hotel, in which temporary MANET is employed in the devices and advanced scenarios like maximization on mobile highway automobiles forming an ad hoc vehicle traffic control network are the civilian deployment examples. MANET nodes are known for their low power, processing, memory resources, and high mobility. Handheld wireless nodes can join and depart such networks on a dynamic basis. The minimum wireless network node transmission range creates multiple hop for transforming the information among the rest of the network. Routing is consequently critical for 
designing MANET. The routing methods in traditional wired networks are commonly based on two algorithms such as connection state routing and distance vector routing. Each router can transmit periodic routing advertisements using both techniques.

Mobile Ad-hoc Networks (MANET) is an ad-hoc wireless network with numerous nodes in which topology changes dynamically and has minimum memory, power, and processing capabilities. Because of the limitations of nodes and the continually changing topology of MANET, network routing system play a critical role. This led to creation of multipath routing in wireless networks, which allows nodes to communicate in various environments. MANET various issues and challenges are listed below;

- Inadequate Power Support.

- Inadequate Bandwidth.

- Network Lifetime.

- End-to-End Delay.

- Quality of Services (QoS).

- Network Security

The organization of this work is described as follows: In section1 introduction is described, in section 2 classification of routing protocols, in section 3 related works are described, in section 4 challenges in Multipath routing is described and in section 5 conclusion part is described.

\section{Routing protocol classifications:}

Ad-Hoc routing protocols are categorized into unipath and multipath protocols, as shown in figure1. AODV and DSR are unipath protocols, whereas multipath protocols are extensions that allow improved network routing. It can also be divided into reactive, proactive, and hybrid. AODV and DSR are two reactive routing protocols that store route information in a routing table. AODV uses the flooding approach to find a route. Route Maintenance and Route Discovery are the two main parameters of both protocols. A single path is used in this protocol in which packets are sent innetwork, making the network vulnerable. 


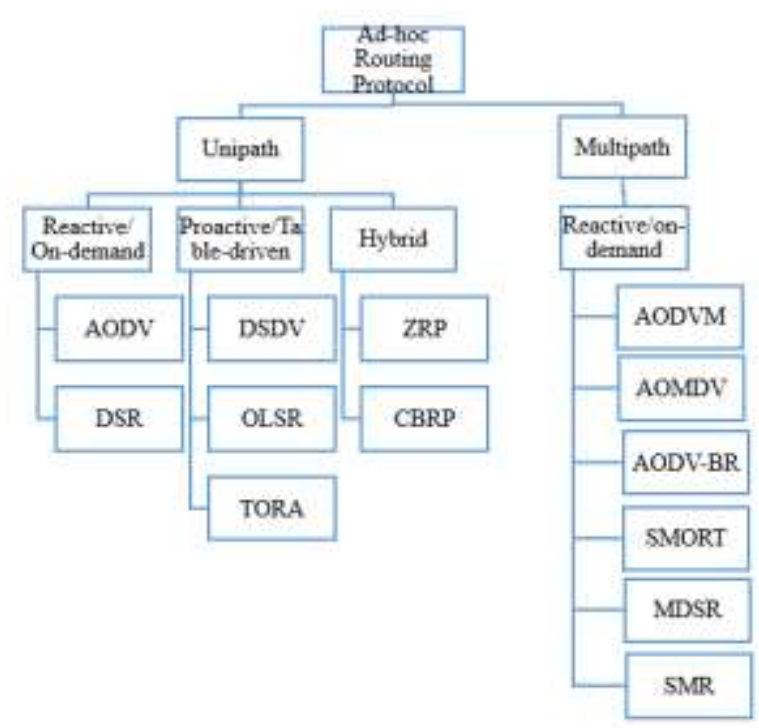

Figure 1- classification of Ad-hoc routing protocols

\subsection{MANETs Multipath Routing:}

MANET routing protocols like DSR and AODV are designed to find a single path from the source node to the destination node. Multipath routing system is the concept of establishing various routes from source and destination. These varied pathways from the source node to destination node pairs can be utilized for accounting the complex and dynamic nature of Mobile ad hoc networks. Multipath routing has various benefits like fault tolerance, increased bandwidth and load balancing. Load balancing can be accomplished by dispersing traffic across several roadways. This should help to ease bottlenecks and traffic overheads. The fault tolerance standpoint creates the continuity on multipath routing. The range can be limited in a wireless network, and routing with single path does not offer a link with sufficient bandwidth. On the other hand, multiple pathways execute data routing simultaneously and the whole paths bandwidth will satisfy the program's bandwidth requirements. When more capacity is available, it is often possible to reduce end-to-end latency. Due to security concerns, it will be more difficult to apply multiple routes for achieving enhanced bandwidth on comparison to the wired networks. Because network nodes communicate across a wireless network, it's critical to be aware of radio intrusion. Transmission overlap is possible to reduce during the transmission from one node path to another node path for achieving the efficiency.

In recent years, several works have been presented in MANETs using multipath routing. We proposed multipath routing systems that improve bandwidth requirements, end-to-end delay minimization, efficiency (fault tolerance), and resource conservation in this segment. The main advantage of the proposed system is the flexibility of DSR over AODV when mixing multipath and unipath routings. Although nodes in DSR keep route supplies, they don't need to keep routing tables with forwarding information as they need in AODV. Forwarding data packets using DSR, there is greater overhead because the entire path must be defined in the packet header. The DSR and AODV are extended with multipath will result in additional benefits and downsides from their parent protocols. The major benefit of SMR is its versatility and multipath addition to DSR. The AODV and DSR permits the intermediate nodes to refer to RREQs by minimizing the route exploration time. 
Whereas SMR and AODVM does not allows the intermediate nodes to respond on discovering path to reach the destination by choosing disjoint paths. AOMDV major feature is it permits the intermediate nodes for answering RREQs even on selecting the disjoint paths.

At intermediate nodes, none of the three multipath protocols refuse any redundant RREQs. It inspires us to think about new ideas. However, path investigation often results in greater overhead messages because of the increased drainage. In multipath protocols, the destination responds to several RREQs, which adds to the overhead. On the other hand, a destination in AOMDV and SMR reacts only to the subset of the RREQs collected. Multipath routing protocols are limited by their complexity and overhead compared to unipath routing systems. The extension of multipath to AODV keeps several routes to a target result which result big routing tables between the intermediate nodes. Packet transmission through multiple routes is discussed in the multipath routing system. Packet reordering will occur as a result of multipath routing. Because only one route is employed, traffic dispersion is not an issue with unipath routing.

\section{Related Works:}

Noor et al. [1] proposed Channel Contention Based Routing (CCBRR) protocol. This system focused on establishing less-divided route among the endpoints. As a result, it will regularize the routing overhead, minimize the packet latency and maximizes the packet distribution ratio. Every intermediate node in the network calculates the channel contention ranking in active data section. If the intermediate node notices the maximization on channel contention, then it will be notified to the source code. Then the source node looks for a less-congested propagation path.

C Perkins et al., in [2] developed an Ad-hoc on-demand Distance Vector routing protocol with simulations and performance evaluation systems. It has resulted that the proposed system is applicable for the network, which contains minimum routing and latency.

L.Wang et al. [3] proposed MSR protocol, a multipath extension of DSR. The proposed contains MSR and probing-based load balancing system for enhancing the throughput, end-to-end delay and drop rate. The major drawback of MST is it results in the maximization of overload processings.

HyukjoonLee, Donghoon Jeon[4] proposed a new multipath routing protocol for MANETs using biological attractor system, improving the network's stability and adaptability to varying situations. The simulation outcomes demonstrate a important change in packet propagation, QoS transmission, and total throughput.

V.Maheshwari et al. [5] proposed delay-aware multipath routing protocol AOMDV for enhancing the QoS in MANETs. It is the AODV extended routing protocol. It minimizes the frequent route that improves QoS and concentrates on error rate metrics, enhancing communication reliabilities and network lifetime.

M.Marina et.al [6] developed on-demand Multipath distance vector routing protocol (AOMDV). It results in establishing node-disjoint paths and loop-free. It minimizes the delay and load along with frequent route discoveries.

Reddeppa Reddy et al. [7] developed an On-demand routing protocol (SMORT) for reducing the routing overhead experienced by route recovery of broken routes using alternate paths. As a result, SMART improves fault tolerance and maximizes the throughput. The Split multipath routing protocol 
based on DSR was demonstrated by Lee and Gerla (2000) in [8]. The major goal of SMR is to lower the frequency of route discovery operations and control the network overhead.

Nasipuri and Das et al. [9] discovered a multipath protocol for minimizing the frequency of query flooding. MDSR protocol address the DSR protocol's flooding problem. It is applicable for the network with minimum node and traffic.

R.K. Sahu and N. Chaudhari. S[10] proposed a new protocol using Energy Reduction Multipath Routing Protocol for MANETs with Recoil Technique (AOMDV-ER). It achieves optimal throughput, packet distribution ratio, overhead routing, and network life. On each node, predictionbased connection lifetime is estimated for reducing the network packet losses. This protocol is categorized into distance mechanism, an advanced path discovery algorithm with residual energy and synchronized recoiled node algorithm. The synchronized recoiled node algorithm removes the overhead routing, reduces network lifetime, sluggish traffic, end-to-end pause and sum of data latency reduction transfers. However on comparison to the newly discovered methods a significant efficiency is achieved by the AOMDV-ER algorithm.

Ali, Stewart, Shahrabi, and Vallavaraj [11] developed a fuzzy logic-based technique to alleviate overheads and reduce end-to-end latency in MANETs. It discovers energy-conscious routing by maintaining delay and load. A fuzzy inference engine provides useable bandwidth, delay, and average load in the proposed approach. In the mobile nodes, fuzzy rules is defined for measuring the chance of traffic delivery from that node. Based on the fuzzy framework efficiency, traffic is dispersed across various fail-safe paths to minimize the load at a congested node.

SungwookKim[12] proposes a contemporary multipath routing technique based on a virtual hardening method. This mechanism attains higher and reciprocal benefits in both the complex real-world network setting and in aggressive also. As a result, the proposed routing system is more efficient in achieving an appropriate solution to the problem of synchronized ad hoc cell network routing.

Bakar, A Zainal, and A. H. Mohsin [13] proposed two protocols such as Signal Amplitude and Congestion Prevention Protocol (SSCA) and Hybrid Geo-Cast Routing (HGR) protocol for achieving optimal resource utilization. To reduce overhead capacity, the optimal and versatile HGR protocol leverages geographical location information to constrain the search region throughout the route discovery method by utilizing only promising search paths. Adaptive SSCA, on the other hand, uses the SSCA method to improve compatibility and node accuracy detection, as well as decrease packet decline.

T. Senthilkumaran and V. Sankaranarayanan [14] propose detecting and controlling dynamic congestion routing (DCDR) for ad hoc networks based on average queue duration estimations at the node level. A node uses the average queue duration to detect the current congestion level and sends an alarm note to its neighbors. And the neighbors decide to take a different route to the objective, one that is less polluting. This sophisticated congestion prediction mechanism, which aids congestion control in ad hoc networks, promotes efficient interaction inside the MANET.

To provide load balancing and prevent MANET congestion, Soundararajan, S., and Bhuvaneswaran, R. S et al. [15] developed a scalable multipath routing protocol operated by congestion. The multipath route searching algorithm produces different fail-safe pathways containing multiple routes to reach the destination. The multiple fail-safe paths offer residual electricity, high battery power and minimum loaded nodes. The nodes load along with route outdoes the certain threshold value then on 
the congested connection traffic is circulated over discontinuous multipath routes for managing the traffic burdens.

\begin{tabular}{|c|c|c|c|c|}
\hline S.No & Authors & Algorithms & Advantage & Disadvantage \\
\hline 1 & $\begin{array}{l}\text { Noor Mast, } \\
\text { Muhammad Altaf } \\
\text { Khan, M. Irfan } \\
\text { Uddin, Atif Khan, } \\
\text { Mahmoud Ahmad } \\
\text { Al-Khasawneh, } \\
\text { Syed Atif Ali } \\
\text { Shah, Marwan } \\
\text { Mahmoud [1] }\end{array}$ & $\begin{array}{l}\text { CBBR, an adaptive routing protocol, is } \\
\text { proposed. It maximizes the packet } \\
\text { bandwidth and minimizes the routing } \\
\text { overheads. It discovers minimum divisive } \\
\text { routes from source to destination. A } \\
\text { notification is sent to the source node if } \\
\text { any obstacle occurs in the path and the } \\
\text { source nodes transfer the packet in } \\
\text { another path. }\end{array}$ & $\begin{array}{l}\text { It depends on } \\
\text { AODV in terms } \\
\text { of packet } \\
\text { transmission. }\end{array}$ & $\begin{array}{l}\text { It will work on } \\
\text { a static node } \\
\text { only }\end{array}$ \\
\hline 2 & $\begin{array}{l}\text { Perkins, Charles } \\
\text { E., and Elizabeth } \\
\text { M. Royer }\end{array}$ & $\begin{array}{l}\text { AODV }- \text { It is implemented with } \\
\text { simulations and a performance evaluation } \\
\text { system }\end{array}$ & $\begin{array}{l}\text { It is suitable for } \\
\text { limited routing } \\
\text { constructing } \\
\text { latency. }\end{array}$ & $\begin{array}{ll}\text { It will not be } \\
\text { applicable } & \\
\text { large } & \text { or } \\
\text { dynamic } & \\
\text { networks } & \end{array}$ \\
\hline 3 & $\begin{array}{l}\text { HyukjoonLee } \\
\text { DonghoonJeon }\end{array}$ & $\begin{array}{l}\text { MMQR is an OFDM-TDMA mesh } \\
\text { network multipath routing system that } \\
\text { employs a large number of routes that } \\
\text { may be immediately substituted if one } \\
\text { fails. According to heuristic attractor } \\
\text { selection method biological entities reacts } \\
\text { fast according to the varying situations. } \\
\text { The MMQR is enhanced in this paper so } \\
\text { the mechanism can record adaptively and } \\
\text { reordered according to the contact } \\
\text { environment changes. }\end{array}$ & $\begin{array}{l}\text { The proposed } \\
\text { system enhances } \\
\text { current multipath } \\
\text { routing protocols } \\
\text { regarding packet } \\
\text { transmission } \\
\text { ratio, QoS, and } \\
\text { throughput. }\end{array}$ & $\begin{array}{l}\text { Lack of } \\
\text { reliability in } \\
\text { selecting the } \\
\text { routes. }\end{array}$ \\
\hline 4 & $\begin{array}{l}\text { Maheshwari, } \\
\text { Vipul, and } \\
\text { Shrikant Jadhav }\end{array}$ & $\begin{array}{l}\text { AOMDV is a delay-aware multipath } \\
\text { routing protocol developed for enhancing } \\
\text { the QoS in MANETs. It is the extension } \\
\text { of the AODV routing protocol }\end{array}$ & $\begin{array}{l}\text { Effective in load } \\
\text { balances }\end{array}$ & $\begin{array}{l}\text { Increase in } \\
\text { memory and } \\
\text { routing } \\
\text { overheads }\end{array}$ \\
\hline 5 & $\begin{array}{l}\text { Sahu, } \quad \text { R.K.; } \\
\text { Chaudhari, N.S }\end{array}$ & $\begin{array}{l}\text { In terms of energy utilization, packet } \\
\text { delivery ratio (PDR), routing overhead } \\
\text { and network lifetime the proposed } \\
\text { AOMDV-ER performance is more } \\
\text { efficient than the existing algorithms like } \\
\text { SRMP, AOMDV, and AOMR-LM. In the } \\
\text { AOMDV-ER protocol nodes perceptively } \\
\text { executes the packet transmission using } \\
\text { variable recoil times according to its } \\
\text { geographical role. }\end{array}$ & $\begin{array}{l}\text { It minimizes the } \\
\text { transmission and } \\
\text { maximizes the } \\
\text { network lifetime } \\
\text { than the other } \\
\text { AODV based } \\
\text { algorithms. }\end{array}$ & $\begin{array}{l}\text { Lack } \\
\text { accuracy } \\
\text { network } \\
\text { lifetime. }\end{array}$ \\
\hline 6 & $\begin{array}{l}\text { Ali, M., Stewart, } \\
\text { B. G., Shahrabi, }\end{array}$ & $\begin{array}{l}\text { A load and energy-conscious multipath } \\
\text { routing protocol based on fuzzy logic has }\end{array}$ & $\begin{array}{l}\text { The proposed } \\
\text { simulation result }\end{array}$ & $\begin{array}{l}\text { Overhead is } \\
\text { more and the }\end{array}$ \\
\hline
\end{tabular}




\begin{tabular}{|c|c|c|c|c|}
\hline & $\begin{array}{l}\text { A., \&Vallavaraj, } \\
\text { A }\end{array}$ & $\begin{array}{l}\text { been proposed MANETs. A fuzzy } \\
\text { inference engine uses load, residual } \\
\text { energy, bandwidth, and delay as the input } \\
\text { for determining the traffic based on the } \\
\text { fuzzy rule. Traffic is distributed over } \\
\text { numerous fail-safe routes to the } \\
\text { destination based on the fuzzy system's } \\
\text { output to alleviate the load at a congested } \\
\text { node. }\end{array}$ & 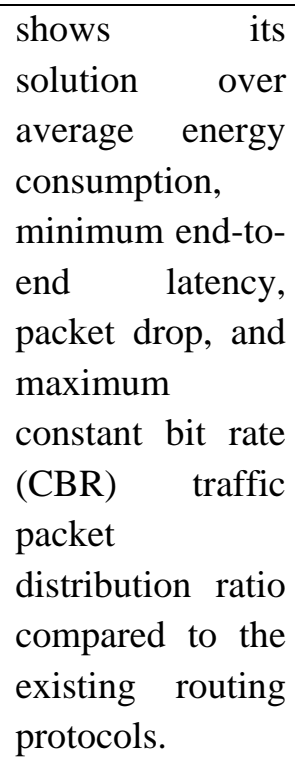 & $\begin{array}{l}\text { protocol is } \\
\text { applicable only } \\
\text { for } \quad \text { CBR } \\
\text { traffic. }\end{array}$ \\
\hline 7 & Sungwook Kim & $\begin{array}{l}\text { A modern multipath routing algorithm is } \\
\text { developed using powerful simulated } \\
\text { annealing method. The suggested scheme } \\
\text { is designed for dynamic, self-organizing, } \\
\text { online, and immersive network execution. } \\
\text { As a result, each node can have advanced } \\
\text { adaptive control system and discover an } \\
\text { acceptable path, allowing for local } \\
\text { routing. This approach will dynamically } \\
\text { rearrange the defined route to respond to } \\
\text { network changes in complicated network } \\
\text { situations. }\end{array}$ & $\begin{array}{l}\text { The simulation } \\
\text { shows better } \\
\text { performances } \\
\text { than the existing } \\
\text { protocols. }\end{array}$ & \\
\hline 8 & $\begin{array}{l}\text { T. } \\
\text { Senthilkumaran } \\
\text { and V. } \\
\text { Sankaranarayanan }\end{array}$ & $\begin{array}{l}\text { A unique, complicated congestion } \\
\text { prediction system was proposed to assess } \\
\text { traffic variability and accurately classify } \\
\text { the congestion state. The nodes } \\
\text { congestion status is determined along } \\
\text { with the path. DCDR applies alternate } \\
\text { route for controlling the congestions. }\end{array}$ & $\begin{array}{l}\text { Minimum } \\
\text { latency, } \\
\text { Improved packet } \\
\text { delivery ratio, } \\
\text { and better } \\
\text { performance than } \\
\text { the traditional } \\
\text { protocols. }\end{array}$ & $\begin{array}{l}\text { On high traffic } \\
\text { possibility } \\
\text { packet loss }\end{array}$ \\
\hline 9 & $\begin{array}{l}\text { Soundararajan, S. } \\
\text { \&Bhuvaneswaran, } \\
\text { R. S }\end{array}$ & $\begin{array}{l}\text { A multipath routing protocol based on } \\
\text { congestion was developed to provide load } \\
\text { balancing and avoid congestion } \\
\text { (MANETs). The multipath route } \\
\text { searching algorithm estimates various } \\
\text { fail-safe paths to the destination for all } \\
\text { intermediate nodes on the primary path. } \\
\text { The multiple fail-safe paths supply the } \\
\text { least overburdened nodes and extra } \\
\text { bandwidth and capacity. }\end{array}$ & $\begin{array}{lr}\text { Effective in load } \\
\text { balance, fault } \\
\text { tolerance, and } \\
\text { network } \\
\text { congestion }\end{array}$ & $\begin{array}{l}\text { Routing } \\
\text { overhead } \\
\text { high. }\end{array}$ \\
\hline 10 & Smart & $\begin{array}{l}\text { It is a fail-safe multipath routing system. } \\
\text { It replaces the primary with the new path. }\end{array}$ & $\begin{array}{l}\text { Minimum } \\
\text { overhead }\end{array}$ & $\begin{array}{l}\text { Multiple Paths } \\
\text { maximizes the }\end{array}$ \\
\hline
\end{tabular}




\begin{tabular}{|l|l|l|l|l|}
\hline & & $\begin{array}{l}\text { maximum } \\
\text { lifetime at large } \\
\text { networks also }\end{array}$ & $\begin{array}{l}\text { Overhead on } \\
\text { Transmission } \\
\text { Of Rerr Over }\end{array}$ \\
\hline
\end{tabular}

Table 1- Comparison of multipath routing protocols in manet

\section{Challenges in Multipath routing:}

For achieving efficient ad hoc networks service, several factors are required, including scaling, resilience, reliability, energy limitations, mobility, and severe node density. Most of the approaches evolved for solving these issues are based on a single routing solution. Hence, a multipath routing mechanism is required for ad hoc cell wireless networks. Finding a more robust alternative to existing protocols or making significant adjustments to an existing procedure looks to be significant. Some critical issues are also under-discussed, despite being outside the scope of established standards. Ad hoc routing techniques, for example, frequently run into problems when the radio communication characteristics of the environment are complex. The urban settings with multiple nodes indoors or distributed around tunnel locations are the examples of this case. In certain cases, the accessible pathways can be quite winding, and not all protocols will find even one, let alone many. Few of the most recent approaches have taken safety into account. It is hard to deliver key values according to the mobile wireless world, and security measures have high overheads. The ad hoc wireless system's safety standards, on the other hand, are more complex than those of a regular wired network, making safety important. Attacks on wireless networks are becoming more common as a result of the vulnerability of commonly used protocols.

The ad hoc network protocol proposed is not considerably safer than wired protocols, especially when compromised network nodes. It will be interesting to see any specific safety problems when building multiple routes instead of single route. Definitely, the protocols' architecture can ensure that good pathways are always appropriately generated, even when malicious members are present. Developments in ad hoc multipath routing are accelerating in anticipation of the increased need for such networks. On protocol design standards, an agreement would almost certainly be reached soon. Much more study is needed in this area to ensure that multipath routing algorithms are a good choice for mobile ad hoc wireless networks in the future.

\section{Conclusion:}

Recently, Mobile Ad-hoc Networks (MANETs) have been among the most popular domains among the research communities. Several works are evolved in the perspective of achieving efficient routing protocol. The major requirements for a successful routing protocol are QoS, load balancing, compatibility, energy control, and fault tolerance. The existing routing protocols are not capable of achieving reliable network efficiency. Achieving network efficiency with a single routing path mechanism is complex. Hence multipath routing protocols for MANETs are defined in this paper. This article includes the study of various protocols and their implementation, efficiency, and challenges in discovering an efficient Multipath routing protocol. The primary thing that needs to consider is durability, low overhead, scalability, and energy performance. This study will help the researchers identify the drawbacks and develop a new or enhancing the existing multipath routing protocol for MANET. 


\section{Reference:}

1) Noor Mast, Muhammad Altaf Khan, M. Irfan Uddin, Syed Atif Ali Shah, Atif Khan, Mahmoud Ahmad Al-Khasawneh, Marwan Mahmoud, "Channel Contention-Based Routing Protocol for Wireless Ad Hoc Networks", Complexity, vol. 2021, Article ID 2051796, 10 pages, 2021.

2) Perkins, Charles E., and Elizabeth M. Royer. "Ad-hoc on-demand distance vector routing." In Mobile Computing Systems and Applications, 1999. Proceedings. WMCSA'99. Second IEEE Workshop on, pp. 90-100. IEEE, 1999.

3) Wang, Lei, Lianfang Zhang, Yantai Shu, and Miao Dong. "Multipath source routing in wireless ad hoc networks." In Electrical and Computer Engineering, 2000 Canadian Conference on, vol. 1, pp. 479-483. IEEE, 2000.

4) HyukjoonLee,Donghoon Jeon "A mobile ad-hoc network multipath routing protocol based on biological attractor selection for disaster recovery communication" 22 October 2015. Express, Volume, September 2015, Pages 86-89.

5) Maheshwari, Vipul, and Shrikant Jadhav. "Article: Survey on MANET Routing Protocol and Multipath Extension in AODV\}." International Journal of Applied 2: 1-6.

6) Marina, Mahesh K., and Samir R. Das. "Ad hoc on-demand multipath distance vector routing." Wireless Communications and Mobile Computing 6, no. 7 (2006): 969-988.

7) Reddeppa Reddy, L., and S. V. Raghavan. "SMORT: Scalable multipath on-demand routing for mobile ad hoc networks." Ad Hoc Networks 5, no. 2 (2007): 162-188.

8) Tarique, Mohammed, Kemal E. Tepe, Sasan Adibi, and Shervin Erfani. "Survey of multipath routing protocols for mobile ad hoc networks." Journal of Network and Computer Applications 32, no. 6 (2009): 1125-1143.

9) Lee, Sung-Ju, and Mario Gerla. "Split multipath routing with maximally disjoint paths in ad hoc networks." In Communications, 2001. ICC 2001. IEEE International Conference on, vol. 10, pp. 3201-3205. IEEE, 2001.

10) Sahu, R.K.; Chaudhari, N.S. Energy Reduction Multipath Routing Protocol for MANET Using Recoil Technique. Electronics 2018, 7, 56.

11) Ali, M., Stewart, B. G., Shahrabi, A., \&Vallavaraj, A. "Fuzzy based load and energy-aware multipath routing for mobile ad hoc networks" International Journal of Computer Applications, 114(16), 25-32.

12) Sungwook Kim "Adaptive MANET Multipath Routing Algorithm Based on the Simulated Annealing Approach" Published 16 June 2014, Hindawi Publishing Corporation $\square$ e Scientific World Journal Volume 2014, Article ID 872526, 8 pages.

13) A. H. Mohsin, K. A. Bakar, and A. Zainal, "Optimal control overhead based multi-metric routing for MANET,” Wireless Networks, vol. 24, no. 6, pp. 2319-2335, 2018.

14) T. Senthilkumaran and V. Sankaranarayanan, "Dynamic congestion detection and control routing in ad hoc networks," Journal of King Saud University - Computer and Information Sciences, vol. 25, no. 1, pp. 25-34, 2013

15) Soundararajan, S. \&Bhuvaneswaran, R. S.Adaptive Multi-Path Routing for Load Balancing in Mobile Ad Hoc Networks. Journal of Computer Science, 8(5), 648-655. 